\title{
Generation, Characterization, and Impact of Mesopores in Zeolite Catalysts
}

\author{
Sander van Donk, Andries H. Janssen, Johannes H. Bitter, \\ and Krijn P. de Jong* \\ Department of Inorganic Chemistry and Catalysis, Debye Institute, \\ Utrecht University, Utrecht, The Netherlands
}

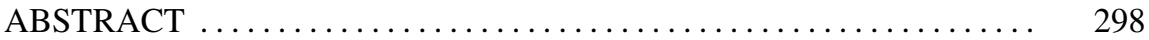

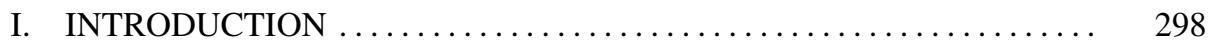

II. GENERATION OF MESOPORES IN ZEOLITES . . . . . . . . . . . . 300

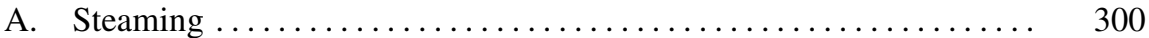

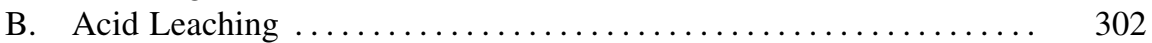

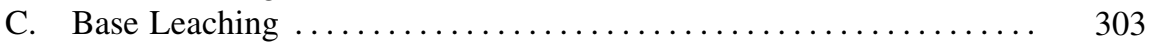

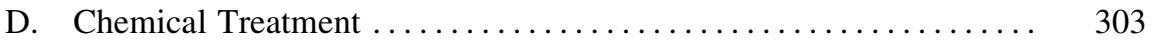

E. Creating Mesopores During Synthesis ................. 303

III. CHARACTERIZATION OF MESOPORES IN ZEOLITES . . . . . . . . 304

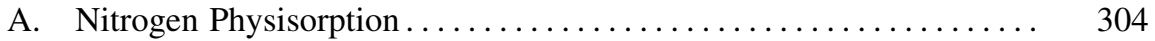

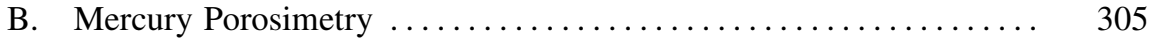

C. Electron Microscopy ......................... 305

IV. TRANSPORT AND REACTION IN ZEOLITES CONTAINING

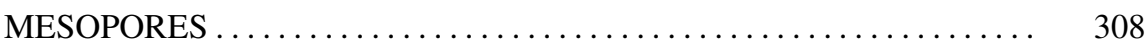

*Correspondence: Krijn P. de Jong, Utrecht University, Department of Inorganic Chemistry and Catalysis, P.O. Box 80083, 3508 TB Utrecht, The Netherlands; Fax: +31 30 2511027; E-mail: K.P.deJong@chem.uu.nl.
\end{abstract}

DOI: $10.1081 / C R-120023908$

Copyright (C) 2003 by Marcel Dekker, Inc.
0161-4940 (Print); 1520-5703 (Online) www.dekker.com 
A. The Beneficial Role of Mesopores in Zeolite Y Catalysts for

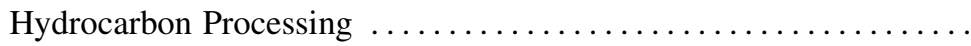

B. The Beneficial Role of Mesopores in Mordenite Catalysts ....... 311

C. The Beneficial Role of Mesopores in Zeolite Catalysts for Fine

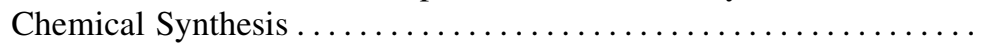

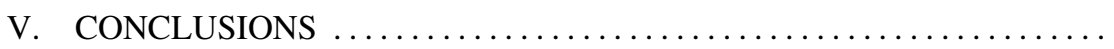

\begin{abstract}
Amongst the current developments in the field of hierarchical pore structures, the creation of mesopores in zeolite crystals is the most frequently employed way to combine micropores with mesopores in one material. In this review an overview is presented of the different approaches to generate and characterize mesopores in zeolite crystals and establish their impact on the catalytic action. Mesopores can be created via several routes from which steaming and acid leaching are the most frequently applied. Novel approaches using secondary carbon templates that are removed after synthesis have recently been launched. For the characterization of mesopores, nitrogen physisorption and electron microscopy are commonly used. More recently, it was shown that electron tomography, a form of three-dimensional transmission electron microscopy, is able to reveal the three-dimensional shape, size, and connectivity of the mesopores. The effect of the presence of mesopores for catalysis is demonstrated for several industrially applied processes that make use of zeolite catalysts: the cracking of heavy oil fractions over zeolite $\mathrm{Y}$, the production of cumene and hydroisomerization of alkanes over mordenite, and synthesis of fine chemicals over Y, ZSM-5, and Beta. For these processes, the mesopores ensure an optimal accessibility and transport of reactants and products, while the zeolite micropores induce the preferred shapeselective properties.
\end{abstract}

Key Words: Zeolites; Mesopores; Micropores; Catalysis; Hydrocarbons; Diffusion.

\title{
I. INTRODUCTION
}

Zeolites are crystalline microporous materials that are widely applied as catalysts in chemical industries like oil refining, basic petrochemistry, and fine chemistry. ${ }^{[1]}$ They exhibit unique properties with respect to both activity and selectivity. Activity is mostly determined by the zeolite Brønsted acid sites and by the active metal-phase that may be deposited into the zeolite. Selectivity is provided by the zeolite micropores that may range in size from $3 \AA$ to $12 \AA$. The shape and size of the micropores may induce various kinds of shape selectivity, as recently reviewed by Marcilly. ${ }^{[2]}$ Besides the highly favorable role in providing shape selectivity, the presence of micropores may in some cases also limit the catalytic performance of zeolites. ${ }^{[3]}$ Cause for this is the restricted molecular transport rate inside the zeolite crystal, induced by the similarity between the size of the involved hydrocarbons and the micropore diameter. Accordingly, the migration of hydrocarbons 
through the micropores of a zeolite occurs in close contact with the micropore walls. The values for zeolite intracrystalline diffusion coefficients are therefore several orders of magnitudes lower than those for the molecular and Knudsen diffusion regimes that are typically displayed in meso- and macroporous media. ${ }^{[4-6]}$ In hydrocarbon transformations over zeolites, both the conversion-level and selectivity may be largely dependent on the time the hydrocarbon molecules spend inside the zeolite crystal. In general one can state that only in the case that the time for diffusion is substantially lower than the time needed for the intrinsic chemical reaction, no limiting effect of diffusion on the overall conversion will be observed and the micropore area of the zeolite is optimally used.

The occurrence of diffusion limitation can be used to the benefit of the catalytic process, for example to enhance the selectivity of the reaction. This is illustrated in the toluene disproportionation and xylene isomerization reaction over ZSM-5, where the diffusion of the desired product $p$-xylene is much faster; that is, the diffusional time constant is much lower than that of the unwanted products $o$-xylene and $m$-xylene. The large difference in diffusivity results in an effective trapping of the unwanted isomers, which only can leave the zeolite micropores easily if they are converted to $p$-xylene. Consequently, the selectivity to $p$-xylene improves with increasing zeolite crystal size ${ }^{[7,8]}$ and is substantially higher than one would expect from the thermodynamic equilibrium.

Nevertheless, in most cases the effective low diffusivity in zeolite crystals limits the reaction rate and yields rather high values for the diffusional time constant. However, the enhancement of intracrystalline diffusion inside a zeolite micropore at a given temperature and pressure seems rather impossible without changing the internal pore architecture. An alternative solution to minimize diffusion limitation is the reduction of the intracrystalline diffusion pathlength. The concept of decreasing the crystal size (i.e., reducing the intracrystalline diffusion pathlength) in order to improve the catalytic performance has been demonstrated for mordenite, ${ }^{[9]}$ zeolite $\mathrm{Y}^{[10]} \mathrm{ZSM}-5,{ }^{[11,12]}$ and zeolite beta. $^{[13]}$ The beneficial effect of the use of small zeolite crystals on the overall reaction rate is twofold. First, smaller crystals have shorter intracrystalline diffusion pathlengths, hence the reaction products are released more rapidly. Accordingly, less secondary reactions like coke formation and cracking are observed. Second, more micropore entrances are present per weight amount of zeolite. This induces a higher accessibility of the zeolite crystals and therefore may result in a net increase in the overall activity. Corma et al. ${ }^{[14]}$ showed that it is even possible to delaminate a zeolite precursor and thereby synthesize small sheets of zeolite that are highly accessible.

In practice the application of small or delaminated zeolite crystals may not always be feasible. Therefore the synthesis of new zeolite materials containing extra-large micropores that enhance a better diffusional transport has recently drawn attention. In this respect, Davis et al. ${ }^{[15,16]}$ presented two new one-dimensional zeolites and recently Corma et al. ${ }^{[17]}$ introduced a new three-dimensional zeolite with highly accessible large cavities present. An alternative route to prepare materials with an enhanced accessibility is the combination of micropores and mesopores (diameter between 2 and $50 \mathrm{~nm}$ ) in one material, since the diffusion in mesopores is several orders of magnitude faster than in micropores. ${ }^{[4]}$ To meet this goal, some recent studies have applied intercrystalline approaches in which zeolite material is assembled into ordered mesoporous structures. This can be either established by the deposition of small zeolite crystals on the walls of the mesopores $^{[18]}$ or by the recrystallization of the amorphous mesopore walls to zeolite 
material while retaining the ordered mesoporous structure. ${ }^{[19,20]}$ However, a more generally applied strategy to attain materials that combine zeolite micropores with mesopores is the intracrystalline approach, in which mesopores are created in the zeolite crystals. In this way the micropores of the zeolite are effectively shortened and their molecular accessibility is largely enhanced. The creation of mesopores in zeolite crystals is equivalent to increasing the external surface area of the zeolite, in this respect that a larger number of pore mouths is made accessible to the reactant. ${ }^{\text {[21] }}$

Lately, numerous examples have become available in which the impact of mesopores on the overall reaction was exposed. In this review we will give a comprehensive overview of the different intracrystalline approaches presented in literature for the generation and characterization of mesopores in zeolite crystals. We will also demonstrate the beneficial effect that the presence of mesopores composes for some industrially applied zeolite catalyzed processes. In that context we will discuss zeolite Y catalysts, which are largely applied in cracking reactions and more recently in some manufacturing processes for fine chemicals and zeolite mordenite, which is applied in the production of cumene and the hydroisomerization of alkanes. Finally, the potential of mesopores in zeolite crystals for fine chemical synthesis is discussed.

\section{GENERATION OF MESOPORES IN ZEOLITES}

\section{A. Steaming}

The most renowned way to create mesopores in zeolites is by hydrothermal treatment in the presence of steam. Although thermal treatments without steam can also create defects in the zeolite structure, ${ }^{[22]}$ the use of steam greatly enhances the mobility of aluminum and silicon species. Almost all the work on steaming of zeolites has been performed on zeolite $\mathrm{Y}^{[23-34]}$ although examples of the steaming of mazzite, ${ }^{[35]}$ omega, ${ }^{[36]}$ mordenite, ${ }^{[37]}$ ferrierite, ${ }^{[38]}$ and ZSM-5 ${ }^{[39]}$ are known. The steaming is usually performed at temperatures above $500^{\circ} \mathrm{C}$ while the zeolite is in the ammonium (or hydrogen) form. During the contacting with steam hydrolysis of $\mathrm{Al}-\mathrm{O}-\mathrm{Si}$ bonds takes place. The aluminum is finally expelled from the framework causing a vacancy (hydroxyl nest) or partial amorphization of the framework. The amorphous material is a source of mobile silicon species, which can heal the vacancies in the framework left by the expelled aluminum atoms. Thus part of the vacancies are filled while others grow to form mesopores, as depicted in Fig. $1{ }^{[40]}$ In regions of high defect concentrations spherical mesopores can coalesce to form channels. ${ }^{[34]}$ Many of the mesopores formed during the steaming are filled with debris from the partial amorphization of the framework and the extraction of aluminum from the framework. The extraframework material in the micro- and mesopores can be extracted by mild acid leaching. Zeolite $\mathrm{Y}$ with very high mesopore volumes of almost exclusively cylindrical mesopores can be obtained after a special hydrothermal treatment at temperatures above $100^{\circ} \mathrm{C}$ and pressures above 1 bar. ${ }^{[41,42]}$ This hydrothermal treatment deviates from steaming, which is performed with gaseous steam at atmospheric pressures. 


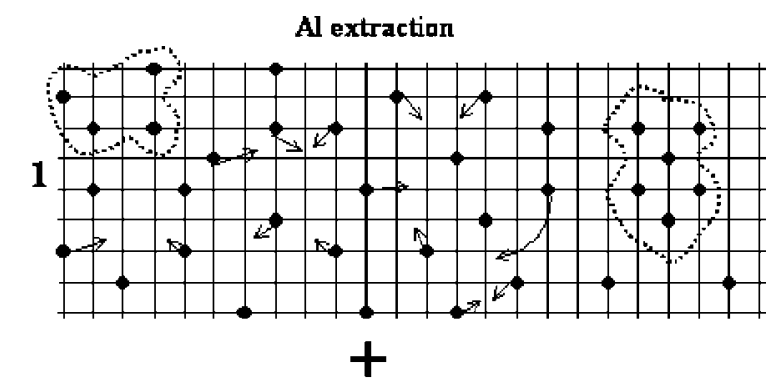

Si Mipration

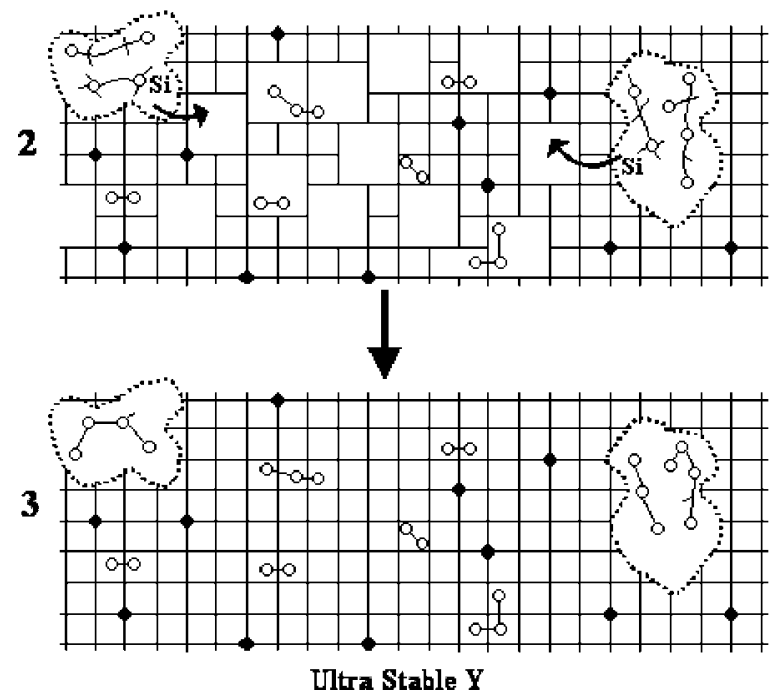

Figure 1. Schematic picture of the formation of mesopores (adapted from Marcilly ${ }^{[40]}$ ). The grid denotes the zeolite framework, the black dots are framework aluminum atoms, the open circles are aluminum atoms extracted from the framework, and the dotted lines indicate the mesopores.

Although the created mesopores are beneficial, the main disadvantage of steaming is the partial amorphization of the zeolite framework. Not only does the relative crystallinity drop with increasing severity of the treatment leading to a decreased amount of the active phase, also part of the micropores and mesopores are filled with amorphous debris leading to a partial blockage of active sites. In Table 1 the drop of the relative crystallinity and the increase of the mesopore volume with increasing treatment are shown for a series of Y zeolites. ${ }^{[42]}$ In Table 1 the deposition of amorphous material on the external surface and in the micropores is also evident from the surface enrichment in aluminum and the lower measured micropore volume compared to the calculated micropore volume that is expected on the basis of the crystallinity, sodium content, and unit cell size of the materials (see Table 1: $\mathrm{V}_{\text {micro }}$ and $\mathrm{V}_{\text {micro }}$ calc.). Upon acid leaching the amorphous material is removed from the meso- and micropores (see Table 1: $\mathrm{V}_{\text {micro }}$ and $\mathrm{V}_{\text {micro }}$ calc. of XVUSY). Another side effect of steaming is that the number and nature of the acid sites is changed by the extraction of aluminum. If only steaming and no acid leaching is applied the bulk 
Table 1. Physical properties of NaY (CBV100), USY (CBV400; steamed), XVUSY (CBV780; steamed twice and acid leached), and High-MesoVUSY (special hydrothermal treatment; see text).

\begin{tabular}{|c|c|c|c|c|c|c|c|c|}
\hline & $\begin{array}{l}\mathrm{Si} / \mathrm{Al} \text { bulk } \\
\text { (at/at) }\end{array}$ & $\begin{array}{l}\mathrm{Si} / \mathrm{Al} \text { XPS } \\
\text { (at/at) }\end{array}$ & $\begin{array}{c}\mathrm{a}_{0} \\
(\mathrm{~nm})\end{array}$ & $\% \mathrm{Y}^{\mathrm{a}}$ & $\begin{array}{l}\mathrm{V}_{\text {micro }} \mathrm{b} \\
(\mathrm{ml} / \mathrm{g})\end{array}$ & $\begin{array}{c}\mathrm{V}_{\text {micro }} \text { calc. } .^{\mathrm{c}} \\
(\mathrm{ml} / \mathrm{g})\end{array}$ & $\begin{array}{l}\mathrm{V}_{\text {tot }}-\mathrm{V}_{\text {micro }} \\
(\mathrm{ml} / \mathrm{g})^{\mathrm{d}}\end{array}$ & $\begin{array}{c}\mathrm{S}_{\mathrm{T}}^{\mathrm{e}} \\
\left(\mathrm{m}^{2} / \mathrm{g}\right)\end{array}$ \\
\hline $\mathrm{NaY}$ & 2.6 & 2.8 & 2.469 & 100 & 0.34 & 0.34 & 0.05 & 8 \\
\hline USY & 2.6 & 1.1 & 2.450 & 87 & 0.26 & 0.32 & 0.11 & 63 \\
\hline XVUSY & 39.3 & 71.3 & 2.423 & 72 & 0.28 & 0.27 & 0.25 & 120 \\
\hline HMVUSY & 5.0 & 1.4 & 2.427 & 71 & 0.15 & 0.26 & 0.47 & 146 \\
\hline
\end{tabular}

${ }^{a}$ Relative crystallinity determined with XRD; data from manufacturer.

${ }^{\mathrm{b}}$ Micropore volume from t-plot.

${ }^{\mathrm{c}}$ Expected micropore volume if all micropores are empty; calculated by correcting $\mathrm{V}_{\text {micro }}$ of $\mathrm{NaY}$ for crystallinity, $\mathrm{a}_{0}$ and sodium weight of USY and XVUSY, and HMVUSY.

${ }^{\mathrm{d}} \mathrm{V}_{\text {meso }}+\mathrm{V}_{\text {macro }}$.

${ }^{\mathrm{e}} \mathrm{Sum}$ of external and mesopore surface area calculated from t-plot.

$\mathrm{Si} / \mathrm{Al}$ ratio remains the same, but the framework $\mathrm{Si} / \mathrm{Al}$ ratio increases. Although these changes of the acid sites can be very important for the catalytic activity and deactivation behavior of the catalyst, this is beyond the scope of this review.

\section{B. Acid Leaching}

The purpose of acid leaching can be the removal of nonframework material created during the steaming process or the direct creation of mesopores, that is, without the use of steam. The first method is frequently applied because during steaming material is extracted from the framework and subsequently deposited in the micro- and mesopores and on the external surface of the zeolite crystals. A mild acid-leaching step, with either inorganic acids such as diluted nitric acid or organic (complexing) acids such as oxalic acid, dissolves this extraframework material. In this case the mesopores are not actually formed during the acid leaching process. Rather, the mesopores formed during the steaming process are emptied, resulting in a higher mesopore volume compared to zeolites that have only been steamed. ${ }^{[25-27,29]}$

In the second method, mesopores are created by direct acid leaching (without steaming). During the severe treatments with strong inorganic acids, aluminum is removed from the framework. The effectiveness of this technique depends on the zeolite used. Especially in the case of mordenite direct acid treatments are used to generate mesopores. ${ }^{[43-48]}$ It has also been claimed that mesopores can be formed in zeolite beta by direct attack with a strong acid ${ }^{[49,50]}$ although it is difficult to separate these intracrystalline mesopores from the mesopores between the very small zeolite beta crystals.

The nature of the acid used can be of great influence on the final mesopore structure. Treating calcined mordenite with acid resulted in a much higher bulk Si/Al ratio and less mesopores in the case of oxalic acid compared to nitric acid. This is thought to be caused by the higher $\mathrm{pH}$ of the oxalic acid solution and the ability of the oxalate ions to form a complex with the aluminum ions. ${ }^{[51]}$ One of the problems with acid leaching is that 
the $\mathrm{Si} / \mathrm{Al}$ ratio is changed. With mild acid leaching after steaming the framework $\mathrm{Si} / \mathrm{Al}$ ratio (obtained after steaming) is not changed if performed carefully. ${ }^{[25,26]}$ However, if mesopores are created by direct attack of the zeolite with acid, the framework Si/Al ratio increases resulting in a loss of active sites. For several purposes one would like to separate the contributions of the changes of the acid sites and the generation of mesopores in order to study their influence on catalytic reactions. With acid leaching both variables are changed at the same time, thus complicating the interpretation of the activity of the catalyst.

\section{Base Leaching}

To our knowledge only a few examples are known of treating a zeolite with a base in order to generate mesopores. Matsukata et al. ${ }^{[52,53]}$ treated ZSM-5 crystals with a $\mathrm{NaOH}$ solution, resulting in a partial dissolution of the zeolite crystals. Higher $\mathrm{NaOH}$ concentrations and prolonged contact of the zeolites with the $\mathrm{NaOH}$ solution resulted in an increase of the external surface and mesopore volume. Recently they have extended the experiments to the base leaching of USY ${ }^{[54]}$ Besides treatment of ZSM-5 with NaOH, ${ }^{[55]}$ treatment of 10 -membered ring zeolites like ferrierite with alkali aluminates ${ }^{[56]}$ is also known in patent literature to increase the porosity of the zeolites. In these cases, however, an additional acid treatment was performed after the base treatment to dissolve amorphous material in the pores.

\section{Chemical Treatment}

Extraction of aluminum from the framework of zeolite $\mathrm{Y}$ by reaction with $\mathrm{SiCl}_{4}$ results in the formation of mesopores, ${ }^{[57]}$ although it has also been reported that it is possible to obtain a dealuminated zeolite $\mathrm{Y}$ without mesopores after reaction with $\mathrm{SiCl}_{4} \cdot{ }^{[24]}$ Extraction of aluminum from zeolite $\mathrm{Y}$ with EDTA ${ }^{[17]}$ or $\left(\mathrm{NH}_{4}\right)_{2} \mathrm{SiF}_{6}{ }^{[58]}$ results in the formation of mesopores. However, it is known that the zeolite structure collapses if the rate of extraction of aluminum by EDTA or $\left(\mathrm{NH}_{4}\right)_{2} \mathrm{SiF}_{6}$ is much faster than the migration of silicon in the framework. ${ }^{[59]}$

\section{E. Creating Mesopores During Synthesis}

Recently researchers from Haldor Topsøe developed a method to create mesopores in zeolite crystals during the synthesis. ${ }^{[60]}$ First they synthesized zeolite crystals around a template carbon source, namely carbon black particles ${ }^{[61]}$ or carbon nanotubes. ${ }^{[62]}$ During the subsequent calcination of the material the carbon is burned away, resulting in

mesopores in the zeolite crystallites. This strategy enables one to tune the size, shape, and connectivity of the mesopore system in the zeolite by choosing the proper carbon source. This also allows one to vary the $\mathrm{Si} / \mathrm{Al}$ ratio and the mesopore system independently. 


\section{CHARACTERIZATION OF MESOPORES IN ZEOLITES}

\section{A. Nitrogen Physisorption}

The most widely applied technique to study the size and surface area of mesopores in zeolites is nitrogen physisorption. Already valuable information on the presence and shape of the mesopores can be deduced from the shape of the nitrogen adsorption and desorption isotherm. In Fig. 2 the curves for the nitrogen adsorption and desorption of some different $\mathrm{Y}$ zeolites are displayed. The NaY zeolite without mesopores will give a type I isotherm, while after the formation of mesopores a combination of type I and IV isotherms is found as is observed for the three USY samples. The existence of a hysteresis loop in the isotherms indicates the presence of mesopores, whereas the shape of the hysteresis loop is related to the shape of the mesopores. ${ }^{[25,29,42]}$ Roughly, a vertical hysteresis loop indicates cylindrical mesopores, whereas a horizontal hysteresis loop indicates inkbottle-type mesopores. However, since most mesopore systems have a broad variation in pore shapes and sizes, this should be treated with caution. From the presence and shapes of the hysteresis loops in Fig. 2, it is obvious that by varying the steaming treatment different amounts and forms of mesopores can be created.

For the analysis of the nitrogen physisorption data several methods are available. Very often only the BET surface of the materials is given. Because for microporous materials the boundary conditions for multilayer adsorption are not fulfilled, the reported BET areas have no physical meaning. They should be understood as a number proportional to the total micropore volume rather than the specific surface area. ${ }^{[63]}$ A valuable tool for the analysis of the external surface area is the t-plot method. The external surface area is the total surface area of all meso- and macropores. If the crystallite size remains the same during the formation of mesopores the difference between the external surface areas of the parent and the treated zeolite is the surface area of the mesopores created. Hudec et al. ${ }^{[45]}$ showed that upon acid leaching of an H-mordenite, the BET surface area remained almost unaltered, while the external surface area increased due to the formation of mesopores. Another method that is often applied is the BJH (Barret-Joyner-Halenda) method, which uses the desorption branch of the nitrogen isotherms to calculate the pore size distribution and the adsorbed volume. Based on the Kelvin equation the BJH method gives a reasonably good pore size distribution up to ca. $4 \mathrm{~nm}$ diameter. However, below a pore diameter of $2 \mathrm{~nm}$ the Kelvin equation is not valid anymore and the area between 2 and $4 \mathrm{~nm}$ is also prone to errors if a hysteresis loop is present. ${ }^{[29,64]}$ In that case a huge amount of nitrogen is released at once between a relative pressure of 0.38 and 0.44 , which is visible as the closing of the hysteresis loop in the isotherm. The BJH method correlates the volume of released nitrogen via the Kelvin equation to pores of 3-4 nm diameter. This is not always correct, because inkbottle type of pores with pore necks smaller than $4 \mathrm{~nm}$ diameter release their nitrogen between a relative pressure of 0.38 and 0.44 . Many examples are known where people claim that uniform pores of $4 \mathrm{~nm}$ diameter are formed, which do not change during more severe treatments. This often leads to discrepancies with TEM images shown. ${ }^{[29,53,65]}$ Sometimes the $\mathrm{BJH}$ method is applied to the adsorption branch of the nitrogen isotherm. However, many programs treat the adsorption isotherm as if it was a desorption isotherm in order to apply the BJH method. Because this gives errors in the calculated pore size distribution, care should be taken when the BJH method is applied to the adsorption branch. 


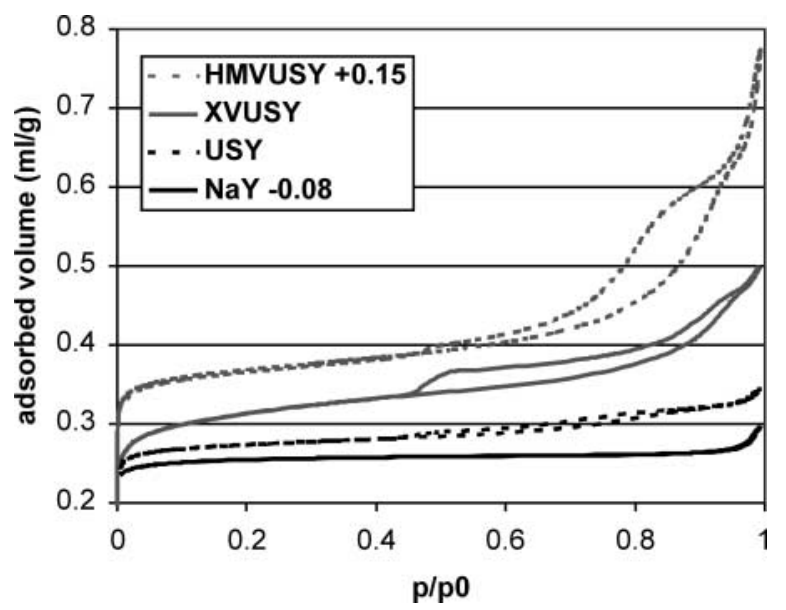

Figure 2. Nitrogen adsorption and desorption isotherms on a series of Y zeolites.

\section{B. Mercury Porosimetry}

In the IUPAC's Recommendations for the Characterization of Porous Solids it is stated that "mercury porosimetry is widely accepted as a standard measure of total pore volume and pore size distribution in the macro- and mesopore ranges.. ${ }^{[66]}$ Nevertheless, only two examples are known to us where researchers used mercury porosimetry to study the intracrystalline mesopores of zeolites. Lohse et al. ${ }^{[23]}$ used mercury porosimetry in addition to adsorption measurements of hexane to show that, upon steaming of zeolite $\mathrm{Y}$, a mesopore system with pores of $10 \mathrm{~nm}$ diameter is formed. After extraction of extraframework material with an acid, the pore diameter increased to $20 \mathrm{~nm}$. More recently Janssen et al. ${ }^{[42]}$ used mercury porosimetry as an extension to nitrogen physisorption measurements to differentiate between cylindrical mesopores and mesopores connected to the external surface by micropores only (cavities). The results are displayed in Fig. 3. From this it is clear that nitrogen physisorption probes both the micro- and the mesopores, while mercury could penetrate only in pores with diameters larger than $4 \mathrm{~nm}$ (at the applied pressures). After steaming of zeolite $\mathrm{Y}$ the relative volume fraction of the mesopores $(4-20 \mathrm{~nm}$ in diameter) that were cavities inside the crystals amounted to $20 \mathrm{vol} \%$, while after more severe steaming combined with acid leaching even $29 \mathrm{vol} \%$ of the mesopores (with diameters of $4-40 \mathrm{~nm}$ ) were cavities inside the crystals.

\section{Electron Microscopy}

Although scanning electron microscopy (SEM) has been used to assess the formation of mesopores by studying the roughening of the surface of zeolite crystals after acid treatments, ${ }^{[51]}$ transmission electron microscopy (TEM) is the most frequently used electron microscopy technique in the study of mesopore formation. In the transmission 

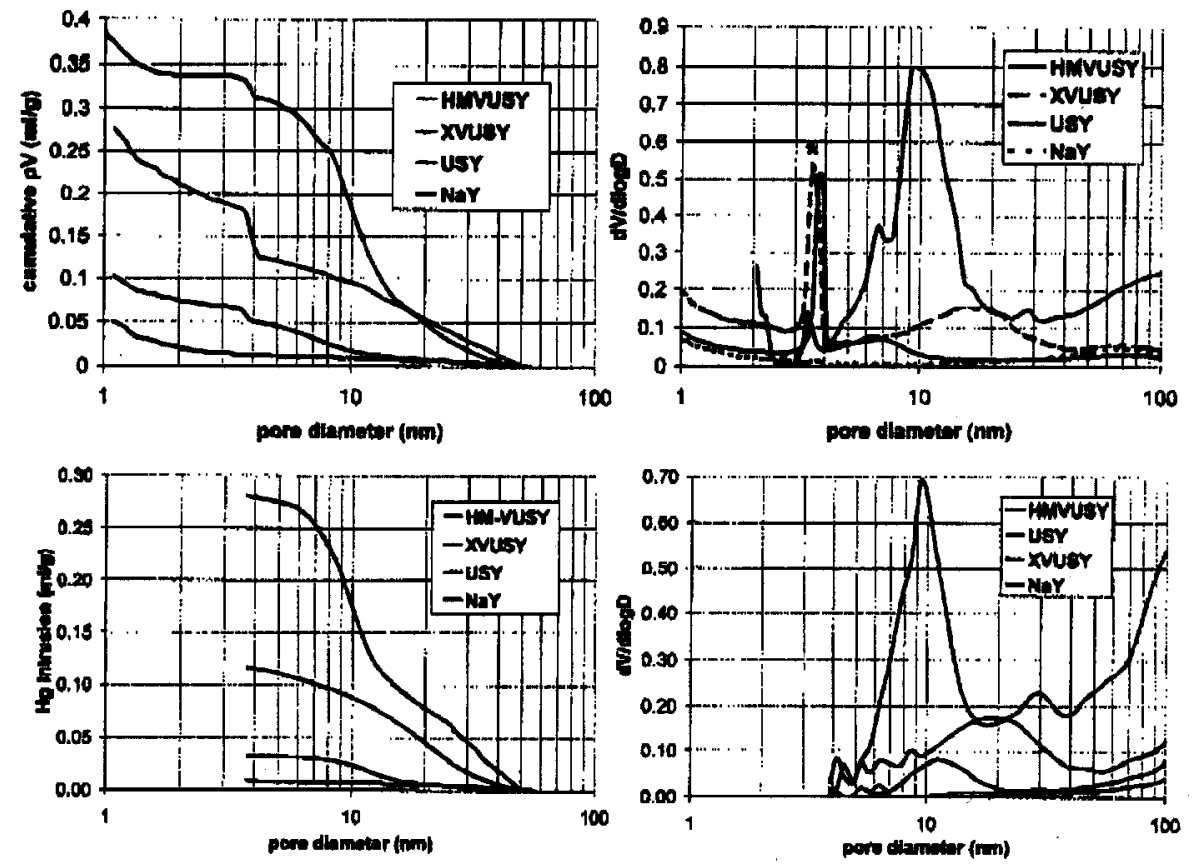

Figure 3. Cumulative nitrogen desorption (upper left) and pore size distribution, calculated from the desorption isotherm using the BJH method (upper right); and cumulative mercury intrusion (bottom left) and calculated pore size distribution (bottom right).

electron microscope an image is formed that is a projection of the mass-density encountered by the electrons moving through the sample. Therefore, a mesopore will show up as a white area in a TEM image since it has a reduced mass-density. This has indeed been observed for zeolite $\mathrm{Y},{ }^{[27,29,30,32-34,49,65,67,68]}$ mordenite, ${ }^{[47,48]} \mathrm{ZSM}-5,{ }^{[53,61,62]}$ ferrierite, ${ }^{[38]}$ mazzite, ${ }^{[35]}$ and zeolite omega. ${ }^{[36]}$ In order to increase the visibility of the mesopores in the TEM images, the crystallites are often cut into thin slices using a microtome ${ }^{[69]}$ However, this gives rise to fracturing of the crystals. Although these fractures are often aligned parallel to each other, they may hinder the interpretation of the TEM image. Because the image formed is a projection of the mass-density of the entire crystallite the exact shape and size of the mesopores is often obscured. After steaming of zeolite $\mathrm{Y}$ the observed mesopores appear spherical, ${ }^{[27,30,65]}$ although Choi-Feng et al. ${ }^{[33]}$ have demonstrated very nicely that in regions with high defect concentrations the mesopores "coalesce" to form channels. Pellet et al. ${ }^{[38]}$ and Ajot et al. ${ }^{[49]}$ have shown that the mesopores in steamed ferrierite and zeolite $\mathrm{Y}$ respectively appear structured. The observed mesopores were square rather than spherical. Also cylindrical mesopores have been observed with TEM. After both leaching of ZSM-5 with $\mathrm{NaOH}^{[53]}$ as well as after templating mesopores in silicalite with carbon nanotubes ${ }^{[62]}$ cylindrical mesopores were clearly visible in the TEM images. Also, Sasaki et al. ${ }^{[32]}$ clearly showed the presence of cylindrical mesopores in steamed zeolite Y. 
In order to get three-dimensional information on the shape of the mesopores Pellet et al. looked at their ferrierite platelets both side-on as well as top-on. ${ }^{[38]}$ However, this was done on different crystals and the projection of mesopores on top of each other obscured a clear interpretation of the shape of the mesopores. Sasaki et al. ${ }^{[32]}$ tilted a steamed zeolite $\mathrm{Y}$ crystal from $0^{\circ}$ to $50^{\circ}$ in their electron microscope while collecting an image every 10 degrees. From these subsequent images it is clear that two round pores that were visible in the crystallite in one orientation showed up as cylindrical pores by tilting over 50 degrees. More recently electron tomography, a form of 3DTEM, has been used to characterize the mesopores in an acid-leached mordenite and a steamed zeolite $Y .^{[70,71]}$ With electron tomography a series of TEM images (tilt series) is taken over a large angular range (typically from $-70^{\circ}$ to $+70^{\circ}$ with $1^{\circ}$ increment). From these data a 3D reconstruction of the crystal is calculated as a stack of very thin slices (ca. $2 \mathrm{~nm}$ ). The tilt series already gives valuable information on the shape of the mesopores, but the slices through the 3D reconstruction really show the mesopores with great clarity and provide information on the three-dimensional shape and connectivity of the mesopores. In Fig. 4a conventional TEM image of a severely steamed and acid leached $\mathrm{Y}$ zeolite and a thin slice through the 3D-TEM reconstruction of the same crystal are given. Although the presence of mesopores can be seen as lighter areas in the conventional TEM image, the mesopores are much clearer (light areas) in the 3DTEM slice. From the study of subsequent 3D-TEM slices it is clear that many of these mesopores are cavities inside the zeolite. ${ }^{[71]}$ In Fig. 5, 3D-TEM slices showing cylindrical mesopores in zeolites are given for an acid leached mordenite ${ }^{[70]}$ and a special hydrothermally treated zeolite $\mathrm{Y}$ (see 2.1). ${ }^{[42]}$ A system of interconnected cylindrical mesopores is expected to enhance accessibility much more than mesoporous cavities inside the crystal. ${ }^{[42]}$
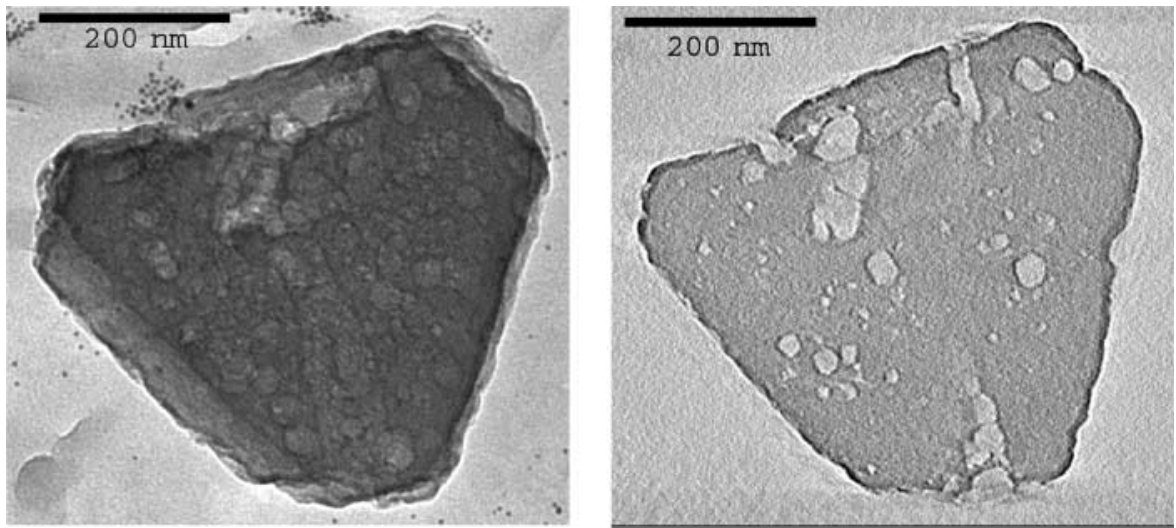

Figure 4. Conventional TEM image of severely steamed and subsequently acid-leached zeolite Y (left) and slice through the 3D-TEM reconstruction of the same crystal (right) showing the mesopores in the crystal as lighter gray tones. 

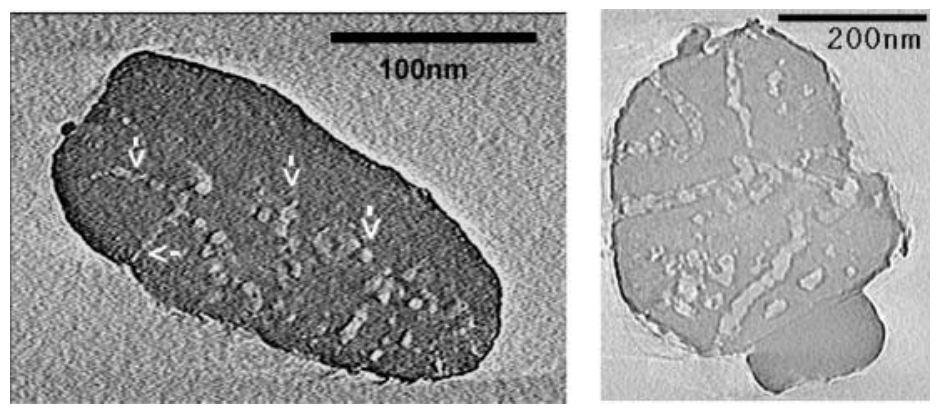

Figure 5. Slices through the crystallites of an acid-leached mordenite (left) and a special hydrothermally treated zeolite Y (HMVUSY, right) based on 3D-TEM reconstructions, showing the mesopores in the crystal as lighter gray tones.

\section{TRANSPORT AND REACTION IN ZEOLITES CONTAINING MESOPORES}

\section{A. The Beneficial Role of Mesopores in Zeolite Y Catalysts for Hydrocarbon Processing}

Zeolite Y catalysts are largely used in hydrocracking and fluid catalytic cracking (FCC) of large bulky molecules of heavy oil fractions into smaller molecules. Nace ${ }^{\text {[72] }}$ demonstrated the limited accessibility of the zeolite Y micropores for the larger molecules present in the feed. Therefore the zeolite is commonly combined with an amorphous matrix that cracks the large molecules into smaller ones, which are then able to access the zeolite micropore system. Additionally, in order to optimize the catalyst performance, the zeolite is steam dealuminated to high $\mathrm{Si} / \mathrm{Al}$ ratios. The dealumination procedure initiates changes in both acidity as well as in the morphology of the zeolite. ${ }^{[32,34,73-79]}$ From literature, it is obvious that a large part of the research has been focussed on explaining the enhanced activity by changes in acidity of the dealuminated zeolite $Y$ catalysts. ${ }^{[78,80-82]}$ However, since diffusion limitation may play a major role in the cracking of large molecules over zeolite Y, morphology changes like mesopore formation largely enhance the activity. ${ }^{[22,73,75-77,83-89]}$ This is made even more so because of the recent trends in FCC reactor and catalyst design resulting in reduced contact times between the catalyst and the hydrocarbons. Accordingly, the mass transfer rates of the reactant into and products out of the zeolite crystals have become more dominant in determining the overall cracking rate. ${ }^{[84-86,89]}$ In addition, the use of heavier and more contaminated feedstocks, containing large bulky molecules and heavy metals, often induce a decrease in accessibility by pore plugging and/or film formation. ${ }^{[86,87]}$ At Akzo Nobel it has been demonstrated that zeolite $\mathrm{Y}$ catalysts displaying a high initial accessibility are less subject to deactivation with time on stream. ${ }^{[84,85,89]}$ In order to increase the initial accessibility, the presence of mesopores is one of the important requirements. The concept of increasing the accessibility of the FCC catalyst and the influence on its catalytic performance has recently been demonstrated by Hakuli et al. ${ }^{[89]}$ who developed a proprietary method to 
measure accessibility, and is displayed in Fig. 6. Although no details about the nature of the accessibility have been published, we speculate that the enhanced conversion and gasoline yield and the lower slurry yield is (partially) due to the effect of the used zeolite Y catalysts containing mesopores in the cracking of oil fractions.

Corma $^{[21,73]}$ showed the favorable effect of the combination of micro- and mesopores in zeolite crystals, by comparing the cracking activity of two dealuminated zeolite Y catalysts. The first catalyst (Y1) had little mesoporosity and an intact micropore system, and the second catalyst (Y2) contained a high amount of mesopores and a micropore system that was partly destroyed. As is displayed in Fig. 7, it was revealed that for the cracking of the relatively small molecule $n$-heptane, which can easily migrate in the micropores, Y1 displayed a higher activity than Y2 as a result of the higher intact micropore system. However, for the cracking of vacuum gas oil, containing mostly molecules that are too large to penetrate into zeolite micropores, Y2 displayed a significantly higher conversion than Y1. A comparable study was performed by Sato et al. ${ }^{[22]}$ for the hydrocracking of diphenylmethane (DPM) and triphenylmethane (TPM) over two different zeolite Y catalysts, one without (Y1) and one with mesopores (Y2). In Fig. 8 it is shown that for the hydrocracking of diphenylmethane, which has a smaller molecular size and therefore is able to diffuse into the zeolite Y micropores, both catalysts exhibited similar activities. On the other hand the hydrocracking of triphenylmethane, which is larger in molecular size and cannot diffuse into the micropores, resulted in a four times higher activity for the catalyst containing mesopores. Falabella et al. ${ }^{\text {[7] }}$ found similar results by comparing the initial cracking rate of 1,3,5-tri-isopropylbenzene over zeolite Y catalysts with different mesoporosities. In this case the used probe molecule was too large to enter the micropores of zeolite $\mathrm{Y}$ and accordingly it was found that catalysts with a higher mesopore volume displayed a higher initial cracking activity.
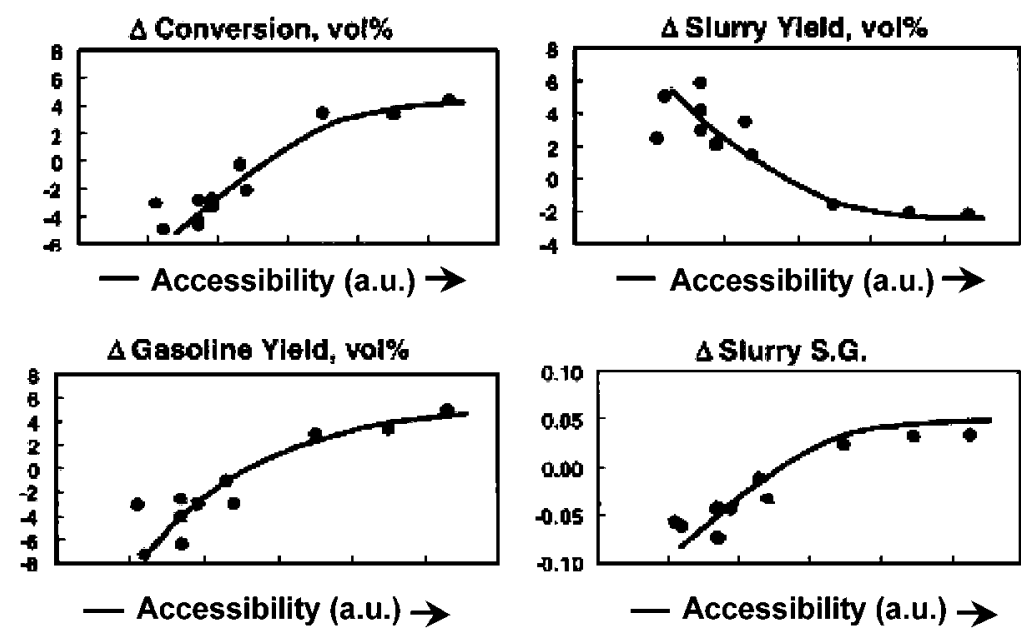

Figure 6. Catalytic performance of an FCC catalyst as a function of accessibility, adapted from Hakuli et al. ${ }^{[89]}$ 

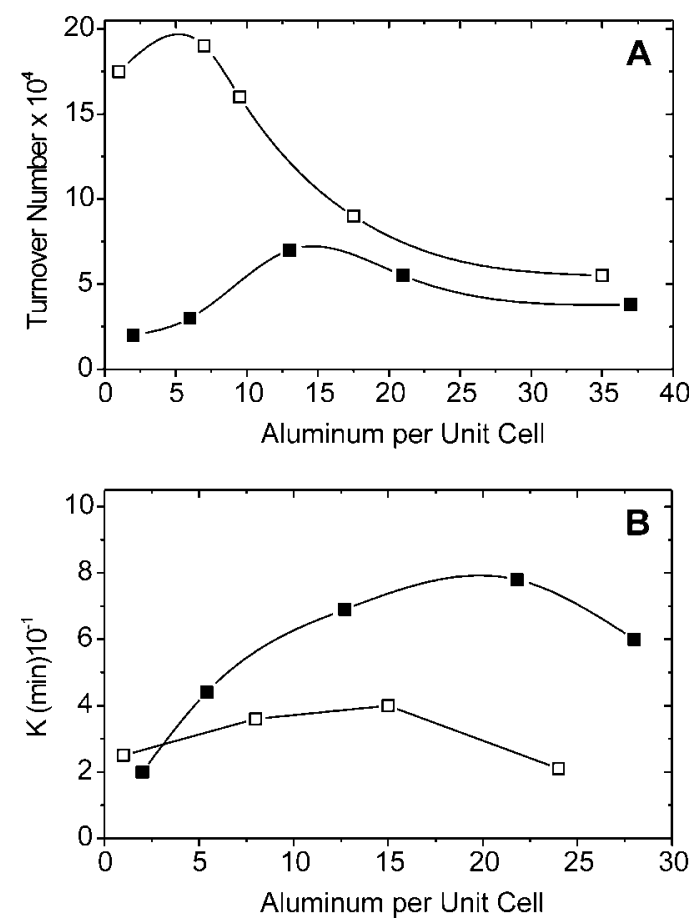

Figure 7. (A) Cracking of $n$-heptane and (B) cracking of vacuum gas oil over dealuminated USY catalysts. Y1 ( $\square$ ) contains little mesoporosity and an intact micropore system and Y2 (ם) contains a high amount of mesopores and a partly destroyed micropore system. Adapted from Corma. ${ }^{[1]}$

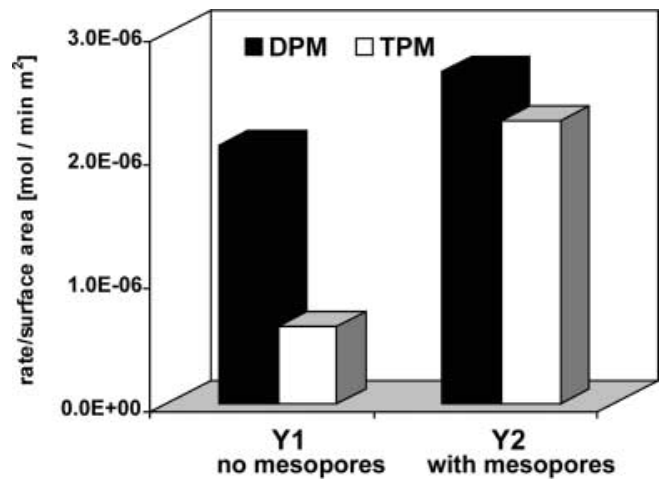

Figure 8. Reaction rate per total surface area for the hydrocracking of diphenylmethane (DPM) and triphenylmethane (TPM) over two different zeolite Y catalysts, one without (Y1) and one with mesopores (Y2), adapted from Sato et al. ${ }^{[22]}$ 


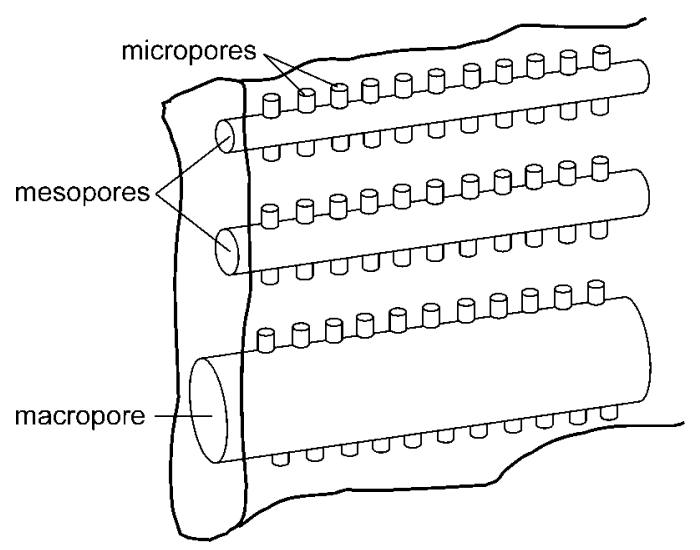

Figure 9. Idealized catalyst pore structure for a cracking catalyst, adapted from Mann. ${ }^{[90]}$

The examples above illustrate that the most favorable zeolite Y cracking catalysts must combine micropores with mesopores. An example of a theoretically ideal cracking catalyst was imagined by Mann ${ }^{[90]}$ and is displayed in Fig. 9, in which the presence of macropores is also visualized. The macro- and mesopores induce a high accessibility of the micropores, enhance diffusion of reactants and products, and provide a high surface area in order to crack large molecules.

\section{B. The Beneficial Role of Mesopores in Mordenite Catalysts}

In general, mordenite catalysts undergo rapid deactivation because of their onedimensional, 12-membered ring pore structure. However, it has been shown that by applying dealumination procedures, mordenite catalysts can be used with high profitability in industrial processes. DOW Chemical applies mordenite catalysts in the production of cumene $^{[91,92]}$ and Shell introduced Pt/mordenite catalysts for the hydroisomerization of linear alkanes to branched ones. ${ }^{[93]}$

Cumene (or isopropylbenzene) is produced by the acid alkylation of benzene with propylene and subsequently used for the production of phenol and acetone. Almost all the applied industrial processes make use of two stages, alkylation and transalkylation, which produces a di-isopropylbenzene (DIPB). The current two-stage DOW-process uses two different deeply dealuminated mordenite catalysts with very high $\mathrm{Si} / \mathrm{Al}$ ratios of 78 and 54, respectively, prepared by several acid leaching and steaming treatments. ${ }^{[43]}$ The high activity and stability of the dealuminated mordenite catalysts have been explained by several factors. ${ }^{[91]}$ First, it is generally established that the concentration of Al cations in the framework largely determines the acid strength of the Brønsted acid sites. ${ }^{[94]}$ After dealumination, the net number of Brønsted sites is lower, but the acid strength of the remaining Brønsted sites is enhanced by the fact that only a small number of aluminum cations is placed in the next nearest neighbor positions. ${ }^{[95]}$ The second explanation is the interaction between the extraframework alumina species present in zeolites after 
dealumination and the Brønsted acid sites. Hong et al ${ }^{[96]}$ and Gruver and Fripiat ${ }^{[97]}$ showed that the initial rate of isomerizaton of $n$-pentane and $o$-xylene over dealuminated mordenites is proportional to the product of the number of Brønsted and Lewis acid sites suggesting a synergetic effect. The third explanation is the removal of obstructions like nonframework species from the micropores, which consequently enhances the diffusivity of the reactant and product molecules. However, the major factor determining the enhanced catalytic performance of the dealuminated mordenites is the presence of mesopores. ${ }^{[44]}$ In this way the one-dimensional mordenite micropores are interconnected by mesopores so that a twoor three-dimensional structure is obtained, as illustrated in Fig. 10. The presence of mesopores decreases the apparent length of the micropores, thereby alleviating diffusion limitation and preventing rapid deactivation. Despite the highly dealuminated structure, it was demonstrated that the catalytic action is still controlled by the shape selective properties of the mordenite 12-membered ring micropores. ${ }^{[43]}$

Alkane hydroisomerization has become one of the most attractive routes for obtaining high-octane quality gasoline. The bifunctional zeolite type catalyst that is industrially applied uses mordenite containing small Pt particles. One of the drawbacks is that the most desired multiple branched products encounter large transport limitation in the one-dimensional pore system of mordenite. ${ }^{[98]}$ To partially overcome this problem the mordenite is mildly acid-leached, resulting in an increase in the Si/Al ratio. ${ }^{[48,98-102]}$ Ideally a $\mathrm{Si} / \mathrm{Al}$ ratio is reached such that no aluminum cations are placed in the next nearest neighbor positions. In this way the cations are just isolated, which induces the highest intrinsic activity ${ }^{[103]}$ and the highest framework stability. ${ }^{[104]}$ Another large beneficial effect of the acid treatment is the introduction of mesopores in the zeolite. ${ }^{[48]}$ The Sachtler group $^{[105]}$ showed the potential positive effect of mesopores on the hydroisomerization activity. A higher hydroisomerization activity was observed for a catalyst with mordenite crystals that were locally destructed due to the growth of large Pt-particles inside. Tromp et al. ${ }^{[48]}$ showed that dealumination by mild acid leaching has a similar effect, because it generates mesopores in the mordenite crystals and consequently enhances the catalytic performance. From the research above it can be concluded that both a shorter diffusion path length as well as an increase in the diffusion coefficient and/or an increase in the intrinsic activity may explain the large increase in catalytic activity.

Recently it was demonstrated that it is possible to combine the measurement of adsorption, diffusion, and reaction in one experimental set-up including a tapered element

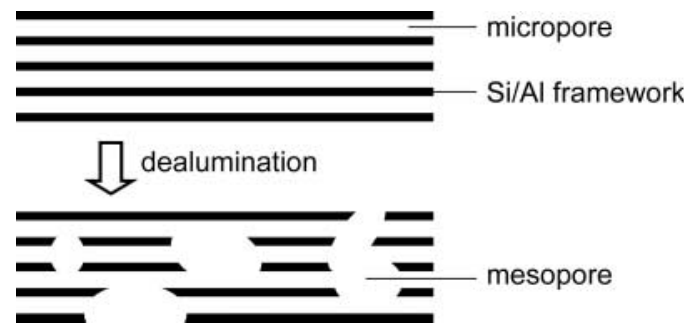

Figure 10. Schematic visualization showing the effect of mesopore creation in zeolite mordenite, adapted from Meima. ${ }^{[44]}$ 
oscillating microbalance (TEOM). ${ }^{[106,107]}$ In this way the effect of acid leaching of the mordenite on the hydroisomerization of $n$-hexane was studied. ${ }^{[107]}$ The $n$-hexane uptakecurves for an untreated $\mathrm{Pt} /$ mordenite (Pt/MOR1) with low $\mathrm{Si} / \mathrm{Al}$ ratio and low mesoporosity, and for an acid-leached $\mathrm{Pt} /$ mordenite (Pt/MOR2) with a high Si/Al ratio and high mesoporosity were measured at reaction temperature. For the latter catalyst, the mesopores are visualized in Fig. 5. The uptake curves are displayed in Fig. 11, from which it is clear that the acid treatment significantly enlarges the rate and amount of $n$-hexane uptake. Since the uptake rate is related to $\mathrm{L}^{2} / \mathrm{D}$, in which $\mathrm{L}$ is the length of the diffusion path and $\mathrm{D}$ the diffusion coefficient, the increased uptake rate can either be explained by a shortening of the diffusion path (L) or an increase in the diffusion coefficient (D). At stabilized uptake, more than a factor four increase in the hydroisomerization rate of $n$-hexane was observed for Pt/MOR2. By applying an adapted Fickian diffusion model and the Thiele theory, it was determined that both an increase of the intrinsic activity as well as an alleviation of intracrystalline diffusion limitation caused the overall activity increase for Pt/MOR2. No difference in the intracrystalline diffusion coefficient was found between $\mathrm{Pt} / \mathrm{MOR} 1$ and Pt/MOR2. It was stated that the enhanced uptake after acid leaching predominantly arises from the shorter intracrystalline diffusion path resulting from the mesoporous structure. The overall increase in hydroisomerization activity as a result of the acid treatment was explained by the enlarged intrinsic activity and by the decrease in the intracrystalline diffusion path length, resulting from the mesoporous structure that enables an enhanced transport of reactant and product molecules.

The above examples clearly demonstrate that the introduction of mesopores in a onedimensional zeolite like mordenite is of major impact with respect to catalytic activity and stability. Part of this is accounted for by acidity enhancements, but the largest beneficial effect is the alleviation of diffusion limitation induced by the presence of mesopores turning the one-dimensional structure into a highly accessible multi-dimensional structure.

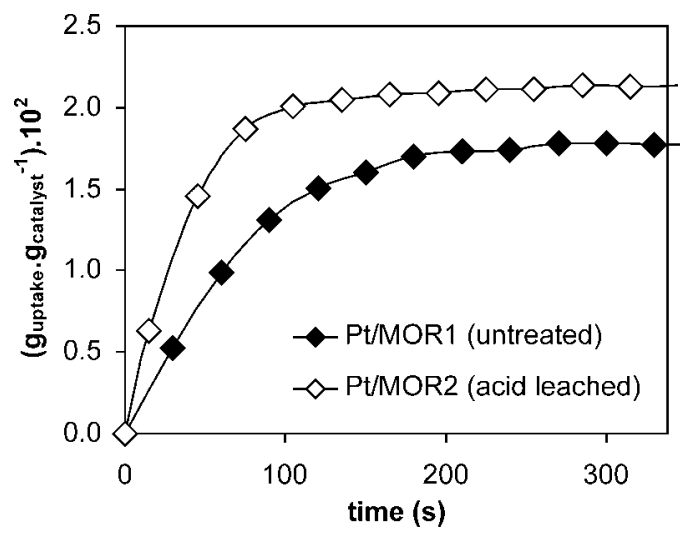

Figure 11. Uptake curves for $n$-hexane in Pt/mordenite before and after acid leaching, obtained at $523 \mathrm{~K}$ in a TEOM. 


\section{The Beneficial Role of Mesopores in Zeolite Catalysts for Fine Chemical Synthesis}

Whereas the use of zeolites in hydrocarbon processing industries is well established, their use in the industrial synthesis of fine chemicals is emerging. One of the main challenges is the fact that the organic chemicals that need to be synthesized are often too bulky to be formed in and to desorb from the zeolite micropore system. ${ }^{[108]}$ Hence, diffusion limitation effects play a major role. Nevertheless, in some cases successful industrial application has been accomplished. Based on the work by Corma et al., ${ }^{[109]}$ Rhodia has commercialized the synthesis of acetoveratrole using dealuminated zeolite $\mathrm{Y}$ catalysts. ${ }^{[10]}$ Moreover, at Dupont it was found that dealuminated zeolite $\mathrm{Y}$ is a selective catalyst for the manufacturing of 1,4-bis(4-phenoxybenzoyl)benzene, which is a monomer for the building of various aromatic polyketons. ${ }^{[111]}$ For both of these reactions it is stated that diffusion limitations may be present and that zeolites with high external surface areas are preferential. More recently Hölderich et al. ${ }^{[112]}$ emphasized the beneficial role of mesopores in zeolite $\mathrm{Y}$ for the selective isomerization of $\alpha$-pinene oxide. As depicted in Fig. 12, it was found that dealuminated Y zeolites exhibit high selectivity toward the preferred campholenic aldehyde. After exposing the sample to a mild acid treatment (HUSY2), a much higher activity as well as a slightly enhanced selectivity was observed. This was explained by the fact that the mesopores formed during the steaming process are emptied by the acid treatment, resulting in a higher mesopore volume compared to the sample that was only steamed (HUSY1). It was stated that the mesopores allow a good diffusional transport of large organic molecules, even at the low temperatures that are often mandatory in fine chemical synthesis.

This does not only hold for Y zeolites but also for zeolite Beta and ZSM-5, which are also used for fine chemical synthesis. Beers et al. ${ }^{[113]}$ showed that the activity of H-Beta and H-USY for the acylation of aromatics (i.e., the acylation of anisol with octanoic acid) could be increased by an optimization of the $\mathrm{Si} / \mathrm{Al}$ ratio in the zeolite and an increase in

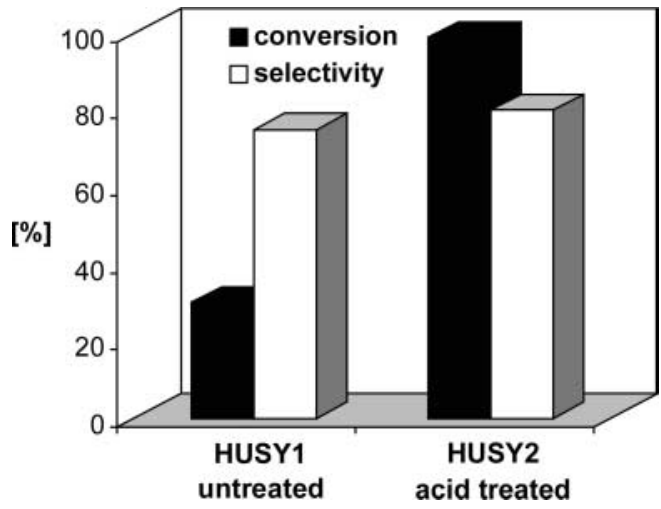

Figure 12. Influence of acid treatment on the performance of HUSY catalysts in the isomerization of $\alpha$-pinene oxide at $273 \mathrm{~K}$, adapted from Hölderich et al. ${ }^{[12]}$ 
the mesoporosity. The same authors also used a ZSM-5 catalyst for this reaction that only displayed a very low activity and did not contain any mesoporosity. Therefore it was concluded that the reaction occurred only on the limited number of active sites on the external surface of the zeolite crystals.

The role of diffusion in H-Beta for the acetalization of glucose in order to prepare alkyl glucoside which are nonionic surfactants was addressed by Camblor et al. ${ }^{[114]}$ It was shown that when crystallites with a size larger than $0.35 \mu \mathrm{m}$ were used, secondary reactions occurred at an appreciable rate resulting in a decrease in the selectivity to the desired primary product. These authors state that when special shape effects are absent but a maximum reaction rate is required, one has to decrease the influence of diffusion through the micropores of the zeolite. This can either be achieved by decreasing the length of the micropores or by increasing the pore diameter.

The above mentioned examples also show that in the fine chemical synthesis mesopores in zeolites can be beneficial. However, the information in the open literature is still scarce on this subject. Some excellent overviews of the use of zeolites in fine chemical synthesis can be found elsewhere. ${ }^{[115-117]}$

\section{CONCLUSIONS}

From this review it is clear that for some applications, like cracking of heavy oil fractions, cumene production, alkane hydroisomerization, and more recently fine chemicals synthesis, the presence of mesopores in zeolite crystals is of major importance. The creation of mesopores can be established via several routes of which steaming and acid leaching are the most common. Characterization of mesopores is mostly performed using nitrogen physisorption and electron microscopy. More recently, however, it was shown that electron tomography, a form of 3D-TEM, is able to reveal the three-dimensional shape, size, and connectivity of the mesopores with great clarity. In order to assess the effect of mesopores on the transport properties of a zeolite catalyst, test reactions using the right probe molecules can be executed or alternatively one can monitor the uptake using a microbalance. Recently a combination of both methods in one set-up was shown to be highly effective in separating physical (transport) and chemical (acidity) effects.

In general, the generation of mesopores in zeolite crystals results in shorter intracrystalline diffusion path lengths and a higher external surface area. Accordingly, the presence of mesopores ensures an optimal accessibility and transport of reactants and products, while the zeolite micropores induce the preferred shape-selective properties. Therefore the combination of micropores and mesopores in one zeolite crystal renders some highly beneficial effects with respect to the catalytic performance.

\section{REFERENCES}

1. Corma, A. Chem. Rev. 1995, 95, 559.

2. Marcilly, C.R. Top. Catal. 2000, 13, 357.

3. Kärger, J.; Ruthven, D.M. Diffusion in Zeolites and Other Microporous Materials; John Wiley and Sons: New York, 1992. 
4. Weisz, P.B. Chemtech 1973, 3, 498.

5. Crank, J. The Mathematics of Diffusion; Clarendon: Oxford, 1975.

6. Ruthven, D.M.; Post, M.F.M. In Introduction to Zeolite Science and Practice, 2nd Ed.; van Bekkum, H., Flanigen, E.M., Jacobs, P.A., Jansen, J.C., Eds.; Elsevier Science: Amsterdam, 2001.

7. Haag, W.O.; Olson, D.H. US Patent 4117026, 1978.

8. Chen, N.Y.; Kaeding, W.W.; Dwyer, F.G. J. Am. Chem. Soc. 1979, 101, 6783.

9. Schwabb, E.A.; Gates, B.C. Ind. Eng. Chem. Fund. 1972, 11, 540.

10. Rajagopalan, K.; Peters, A.W.; Edwards, G.C. Appl. Catal. 1986, 23, 69.

11. Haag, W.O.; Lago, R.M.; Weisz, P.B. Faraday Discuss. 1982, 72, 317.

12. Voogd, P.; van Bekkum, H. Appl. Catal. 1990, 59, 311.

13. Bellussi, G.; Pazzuconi, G.; Perego, C.; Girotti, G.; Terzoni, G. J. Catal. 1995, 157, 227.

14. Corma, A.; Fornes, V.; Pergher, S.B.; Maesen, Th.L.M.; Buglass, J.G. Nature 1998, 396, 353.

15. Freyhardt, C.C.; Tsapatsis, M.; Lobo, R.F.; Balkus, K.J., Jr.; Davis, M.E. Nature 1996, 81, 295.

16. Yoshikawa, M.; Wagner, P.; Lovallo, M.; Tsuji, K.; Takewaki, T.; Chen, C.Y.; Beck, L.W.; Jones, C.; Tsapatsis, M.; Zones, S.I.; Davis, M.E. J. Phys. Chem. B 1998, 102, 7139.

17. Corma, A.; Diaz-Cabanas, M.J.; Martinez-Triguero, J.; Rey, F.; Rius, J. Nature 2002, 418, 514.

18. Karlsson, A.; Stöcker, M.; Schmidt, R. Micropor. Mesopor. Mat. 1999, 27, 181.

19. Kloestra, K.R.; van Bekkum, H.; Jansen, J.C. Chem. Commun. 1997, 23, 2281.

20. Huang, L.; Guo, W.; Deng, P.; Xue, Z.; Li, Q. J. Phys. Chem. B 2000, 104, 2817.

21. Corma, A. Chem. Rev. 1997, 97, 2373.

22. Sato, K.; Nishimura, Y.; Shimada, H. Catal. Lett. 1999, 60, 83.

23. Lohse, U.; Mildebrath, M.Z. Anorg. Allg. Chem. 1981, 476, 126.

24. Scherzer, J. ACS Symp. Ser. 1984, 248, 157.

25. Morin, S.; Ayrault, P.; Gnep, N.S.; Guisnet, M. Appl. Catal. A Gen. 1998, 166, 281.

26. Benazzi, E.; Lynch, J.; Gola, A.; Lacombe, S.; Marcilly, C. Proc. 12th Int. Zeolite Conf. 1999, 2735.

27. Lynch, J.; Raatz, F.; Delande, Ch. Stud. Surf. Sci. Catal. 1987, 39, 547.

28. Beyerlein, R.A.; Choi-Feng, C.; Hall, J.B.; Huggins, B.J.; Ray, G.J. ACS Symp. Ser. 1994, 571, 81.

29. Lynch, J.; Raatz, F.; Dufresne, P. Zeolites 1987, 7, 333.

30. Patzelova, V.; Jaeger, N.I. Zeolites 1987, 7, 240.

31. Zukal, A.; Patzelova, V.; Lohse, U. Zeolites 1986, 6, 133.

32. Sasaki, Y.; Suszuki, T.; Takamura, Y.; Saji, A.; Saka, H. J. Catal. 1998, 178, 94.

33. Choi-Feng, C.; Hall, J.B.; Huggins, B.J.; Beyerlein, R.A. J. Catal. 1993, 140, 395.

34. Beyerlein, R.A.; Choi-Feng, C.; Hall, J.B.; Huggins, B.J.; Ray, G.J. Top. Catal. 1997, 4, 27.

35. Dutartre, R.; Menorval, L.C.D.; Di Renzo, F.; McQueen, D.; Fajula, F.; Schulz, P. Micropor. Mater. 1996, 6, 311.

36. Chauvin, B.; Massiani, P.; Dutartre, R.; Figueras, F.; Fajula, F.; Des Courieres, T. Zeolites 1990, 10, 174.

37. Lee, K.-H.; Ha, B.-H. Micropor. Mesopor. Mat. 1998, 23, 211. 
38. Pellet, R.J.; Casey, D.G.; Huang, H.-M.; Kessler, R.V.; Kuhlman, E.J.; O’Young, C.-L.; Sawicki, R.A.; Ugolini, J.R. J. Catal. 1995, 157, 423.

39. Lago, R.M.; Haag, W.O.; Mikovsky, R.J.; Olson, D.H.; Hellring, S.D.; Schmitt, K.D.; Kerr, G.T. Stud. Surf. Sci. Catal. 1986, 28, 677.

40. Marcilly, C.R. Petrole Et Techniques 1986, 328, 12.

41. Cooper, D.A.; Hastings, T.W.; Hertzenberg, E.P. US Patent 5601798, 1997.

42. Janssen, A.H.; Koster, A.J.; de Jong, K.P. J. Phys. Chem. B. 2002, 106, 11905.

43. Olken, M.M.; Garces, J.M. Proc. 9th Int. Zeolite Conf. 1993, 559.

44. Meima, G.R. CATTECH 1998, 2, 5.

45. Hudec, P.; Novansky, J.; Silhar, S.; Trung, T.N.; Zubek, M.; Madar, J. Ads. Sci. Tech. 1986, 3, 159.

46. Garces, J.M.; Maj, J.J.; Rocke, S.C.; Lee Guo-Shu, J. Eur. Patent 0317907, 1989.

47. Meyers, B.L.; Fleisch, T.H.; Ray, G.J.; Miller, J.T.; Hall, J.B. J. Catal. 1988, $110,82$.

48. Tromp, M.; van Bokhoven, J.A.; Garriga Oostenbrink, M.T.; Bitter, J.H.; de Jong, K.P.; Koningsberger, D.C. J. Catal. 2000, 190, 209.

49. Ajot, H.; Joly, J.F.; Lynch, J.; Raatz, F.; Caullet, P. Stud. Surf. Sci. Catal. 1991, $62,583$.

50. Coutanceau, C.; Da Silva, J.M.; Alvarez, M.F.; Ribeiro, F.R.; Guisnet, M.J. Chim. Phys. 1997, 94, 765.

51. Giudici, R.; Kouwenhoven, H.W.; Prins, R. Appl. Catal. A Gen. 2000, 203, 101.

52. Ogura, M.; Shinomiya, S.; Tateno, J.; Nara, Y.; Kikuchi, E.; Matsukata, M. Chem. Lett. 2000, 8, 882.

53. Ogura, M.; Shinomiya, S.; Tateno, J.; Nara, Y.; Nomura, M.; Kikuchi, E.; Matsukata, M. Appl. Catal. A Gen. 2001, 219, 33.

54. Matsukata, et al. in preparation.

55. Drake, C.A.; Wu, A.-H. US Patent 5952259, 1999.

56. Garces, J.M.; Millar, D.M. US Patent 6017508, 1998.

57. Goyvaerts, D.; Martens, J.A.; Grobet, P.J.; Jacobs, P.A. Stud. Surf. Sci. Catal. 1991, 63, 381 .

58. Triantafillidis, C.S.; Vlessidis, A.G.; Evmiridis, N.P. Ind. Eng. Chem. Res. 2000, $39,307$.

59. Kerr, G.T.; Chester, A.W.; Olson, D.H. Catal. Lett. 1994, 25, 401.

60. Carlsson, A.; Madsen, C.; Schmidt, I.; Houzvicka, J.; Jacobsen, C.J.H. Eur. Patent $1106575,2001$.

61. Jacobsen, C.J.H.; Madsen, C.; Houzvicka, J.; Schmidt, I.; Carlsson, A. J. Am. Chem. Soc. 2000, 122, 7116.

62. Schmidt, I.; Boisen, A.; Gustavsson, E.; Stahl, K.; Pehrson, S.; Dahl, S.; Carlsson, A.; Jacobsen, C.J.H. Chem. Mater. 2001, 13, 4416.

63. van Santen, R.A.; van Leeuwen, P.W.N.M.; Moulijn, J.A.; Averill, B.A. Stud. Surf. Sci. Catal. 1999, 123, 543.

64. Groen, J.C.; Peffer, L.A.A.; Perez-Ramirez, J. Micropor. Mesopor. Mat. 2002, 51, 75.

65. Cartlidge, S.; Nissen, H.-U.; Wessicken, R. Zeolites 1989, 9, 346.

66. Rouquerol, J.; Avnir, D.; Fairbridge, C.W.; Everett, D.H.; Haynes, J.H.; Pernicone, N.; Ramsay, J.D.F.; Sing, K.S.W.; Unger, K.K. Pure Appl. Chem. 1994, 66, 1739. 
67. Horikoshi, H.; Kasahara, S.; Fukushima, T.; Itabashi, K.; Okada, T.; Terasaki, O.I.; Watanabe, D. Bull. Jpn. Chem. Soc. 1989, 3, 398.

68. Ohsuna, T.; Terasaki, O.; Watanabe, D.; Anderson, M.W.; Carr, S.W. Chem. Mater. 1994, 6, 2201.

69. Bovin, J.-O.; Alfredsson, V.; Karlsson, F.; Carlsson, A.; Blum, A.; Terasaki, O. Ultramicroscopy 1996, 62, 277.

70. Koster, A.J.; Ziese, U.; Verkleij, A.J.; Janssen, A.H.; de Jong, K.P. J. Phys. Chem. B 2000, 104, 9368.

71. Janssen, A.H.; Koster, A.J.; de Jong, K.P. Angew. Chem. Int. Ed. 2001, 40, 1102.

72. Nace, D.M. Ind. Eng. Chem. Prod. Res. Dev. 1970, 9, 203.

73. Corma, A. Stud. Surf. Sci. Catal. 1989, 49, 49.

74. Hoek, A.; Huizinga, T.; Esener, A.A.; Maxwell, I.E.; Stork, W.H.J.; van de Meerakker, F.J.; Sy, O. Oil Gas J. 1991, 22, 77.

75. O'Connor, P.; Gevers, A.W.; Humphries, A.P.; Gerritsen, L.A.; Desai, P.H. ACS Symp. Ser. 1987, 375, 318.

76. Kung, H.H.; Williams, B.A.; Babitz, S.M.; Miller, J.T.; Haag, W.O.; Snurr, R.Q. Top. Catal. 2000, 10, 59.

77. Falabella S-Aguiar, E.; Murta-Valle, M.L.; Sobrinho, E.V.; Cardoso, D. Stud. Surf. Sci. Catal. 1995, 97, 417.

78. Biaglow, A.I.; Parrillo, D.J.; Kokotailo, G.T.; Gorte, R.J. J. Catal. 1994, 148, 213.

79. Pine, L.A.; Maher, P.J.; Wachter, W.A. J. Catal. 1984, 85, 66.

80. Cardona-Martinez, N.; Dumesic, J.A. Adv. Catal. 1992, 38, 149.

81. Sommer, J.; Hachoumy, M.; Garin, F. J. Am. Chem. Soc. 1994, 116, 5491.

82. Yaluris, G.; Rekoske, J.E.; Aparicio, L.M.; Madon, R.J.; Dumesic, J.A. J. Catal. 1995, 153, 65.

83. Gosselink, J.W.; van Veen, J.A.R. Stud. Surf. Sci. Catal. 1999, 126, 3.

84. O'Connor, P.; Imhof, P.; Yanik, S.J. Stud. Surf. Sci. Catal. 2001, 134, 299.

85. Kuehler, C.W.; Jonker, R.; Imhof, P.; Yanik, S.J.; O'Connor, P. Stud. Surf. Sci. Catal. 2001, 134, 311.

86. O'Connor, P.; Pouwels, A.C. Stud. Surf. Sci. Catal. 1994, 88, 129.

87. Harding, R.H.; Peters, A.W.; Nee, J.R.D. Appl. Catal. A Gen. 2001, 221, 389.

88. Maxwell, I.E.; Minderhoud, J.K.; Stork, W.H.J.; van Veen, J.A.R. In Handbook of Heterogeneous Catalysis; Ertl, G., Knözinger, H., Weitkamp, J., Eds.; Wiley-VCH: Weinheim, 1997; Vol. 4, 2017.

89. Hakuli, A.K.; Imhof, P.; Kuehler, C.W. Proc. Akzo Nobel Catalysts Symposium, Noordwijk, 2001.

90. Mann, R. Catal. Today 1993, 18, 509.

91. Meima, G.R.; van der Aalst, M.J.M.; Samson, M.S.U.; Garces, J.M.; Lee, G.J. Proc. 9th Int. Zeolite Conf. 1993, 327.

92. Lee, G.J.; Garces, J.M.; Meima, G.R.; van der Aalst, M.J.M. US Patent 325177, 1989.

93. Kouwenhoven, H.W.; van Zijl-Langhout, W.C. Chem. Eng. Prog. 1971, 67, 65.

94. Dwyer, J. Stud. Surf. Sci. Catal. 1987, 37, 333.

95. Karge, H.G.; Dondur, V. J. Phys. Chem. 1990, 94, 765.

96. Hong, Y.; Gruver, V.; Fripiat, J.J. J. Catal. 1994, 150, 421.

97. Gruver, V.; Fripiat, J.J. J. Phys. Chem. 1994, 98, 8549. 
98. Lei, G.D.; Carvill, B.T.; Sachtler, W.M.H. Appl. Catal. A Gen. 1996, 142, 347.

99. Koradia, P.B.; Kiovsky, J.R.; Asim, M.Y. J. Catal. 1980, 66, 290.

100. Maxwell, I.E.; Stork, W.H.J. In Introduction to Zeolite Science and Practice, 2nd Ed.; van Bekkum, H., Flanigen, E.M., Jacobs, P.A., Jansen, J.C., Eds.; Elsevier Science: Amsterdam, 2001.

101. Sie, S.T. Stud. Surf. Sci. Catal. 1994, 85, 587.

102. Corma, A.; Martinez, A. In Catalytic Activation and Functionalisation of Light Alkanes: Advances and Challenges; Derouane, E.G., Haber, J., Lemos, F., Ribeiro, F.R., Guisnet, M., Eds.; Kluwer Academic: Dordrecht, 1998; 35.

103. Guisnet, M.; Fouche, V.; Belloum, M.; Bournonville, J.P.; Travers, C. Appl. Catal. 1991, 71, 283.

104. Guisnet, M.; Fouche, V.; Belloum, M.; Bournonville, J.P.; Travers, C. Appl. Catal. 1991, 71, 295.

105. Carvill, B.T.; Lerner, B.A.; Adelman, B.J.; Tomczak, D.C.; Sachtler, W.M.H. J. Catal. 1993, 144, 1.

106. Chen, D.; Rebo, H.P.; Moljord, K.; Holmen, A. Chem. Eng. Sci. 1996, 51, 2687.

107. van Donk, S.; Broersma, A.; Gijzeman, O.L.J.; van Bokhoven, J.A.; Bitter, J.H.; de Jong, K.P. J. Catal. 2001, 204, 272.

108. Hölderich, W.F.; van Bekkum, H. In Introduction to Zeolite Science and Practice, 2nd Ed.; van Bekkum, H., Flanigen, E.M., Jacobs, P.A., Jansen, J.C., Eds.; Elsevier Science: Amsterdam, 2001.

109. Corma, A.; Climent, M.J.; Garcia, H.; Primo, J. Appl. Catal. 1989, 49, 109.

110. Spagnol, M.; Gilbert, L.; Benazzi, E.; Marcilly, C. WO Patent 9635655, 1996.

111. Corbin, D.R.; Kumpinsky, E.; Vidal, A. Eur. Patent 316133, 1989.

112. Hölderich, W.F.; Röseler, J.; Heitmann, G.; Liebens, A.T. Catal. Today 1997, $37,353$.

113. Beers, A.E.W.; Nijhuis, T.A.; Kapteijn, F.; Moulijn, J.A. Micropor. Mesopor. Mat. 2001, 48, 279.

114. Camblor, M.A.; Corma, A.; Iborra, S.; Miquel, S.; Primo, J.; Valencia, S. J. Catal. 1997, 172, 76 .

115. De Vos, D.E.; Jacobs, P.A. In Zeolites for Cleaner Technologies; Guisnet, M., Gilson, J.-P., Eds.; Catalytic Science Series-Vol 3; Imperial College Press: London, 2002; Chap. 13.

116. Marion, P.; Jacquot, R.; Ratton, S.; Guisnet, M. In Zeolites for Cleaner Technologies; Guisnet, M., Gilson, J.-P., Eds.; Catalytic Science Series-Vol 3; Imperial College Press: London, 2002; Chap. 14.

117. Höldrich, W.F.; Laufer, M.C. In Zeolites for Cleaner Technologies; Guisnet, M., Gilson, J.-P., Eds.; Catalytic Science Series-Vol 3; Imperial College Press: London, 2002; Chap. 15. 